\title{
Schweinegrippe, Antibiotikaresistenzen und Twitter
}

\section{Auswirkungen der Globalisierung auf Verbreitung von Krankheiten und Informationsaustausch}

Schweinegrippe und neue oder wiederkehrende Infektionskrankheiten, die anhaltende Krise der Antibiotika und Probleme der Spitalsinfektionen und nicht zuletzt die Rolle sozialer Medien im globalen Informationsaustausch bildeten einige der Schwerpunkte des diesjährigen der Europäischen Kongresses für klinische Mikrobiologie und Infektionskrankheiten (ECCMID) Anfang April in Wien. Die zunehmende Mobilität der Menschen hat jedenfalls schwerwiegende Folgen für die Ausbreitung von Infektionen.

„Wir hatten ein bewegtes Jahr“, stellte Prof. Javier Garau, der Präsident der Europäischen Gesellschaft für klinische Mikrobiologie und Infektionskrankheiten (ESCMID), bezüglich der durch H1N1 verursachten Grippe, also der Schweinegrippe, fest. Vorwürfe der Öffentlichkeit und der Presse, die Entwicklung einer Impfung sei unverhältnismäßig beschleunigt worden, wies er zurück: „Die Impfungen sind sicher. Wir haben viel gelernt und wir sind froh, dass aufgrund unserer internationalen Zusammenarbeit die Ausbreitung nicht so schlimm war, wie zunächst befürchtet." Gelernt habe man beispielsweise, dass das H1N1 Virus sich in den tiefen Atemwegen vermehrt und eine Infektion, die in diesem Bereich lokalisiert ist, daher am gefährlichsten und langwierigsten sei, und dass Infizierte aus Risikogruppen, wie onkologische Patienten, so früh wie möglich antiviral behandelt werden sollten. Ein Phänomen, das künftig von den Epidemiologen besser genützt werden soll, ist der Austausch der Informationen über das Internet: Über das Netzwerk Twitter und andere soziale Medienseiten bildete sich bei der Schweinegrippe eine Art Frühwarnsystem für Krankheitsausbrüche. Eine Studie fand mehr als eine Million Meldungen über Symptome und grippebezogene Krankheiten während einer viermonatigen Beobachtungsphase.

\section{Mobilität auch für resistente Bakterien}

Die Resistenzentwicklung in Bakterien gegenüber Antibiotika stellt die Mikrobiologen und Infektiologen weiterhin und in zunehmendem Maße vor große Probleme:

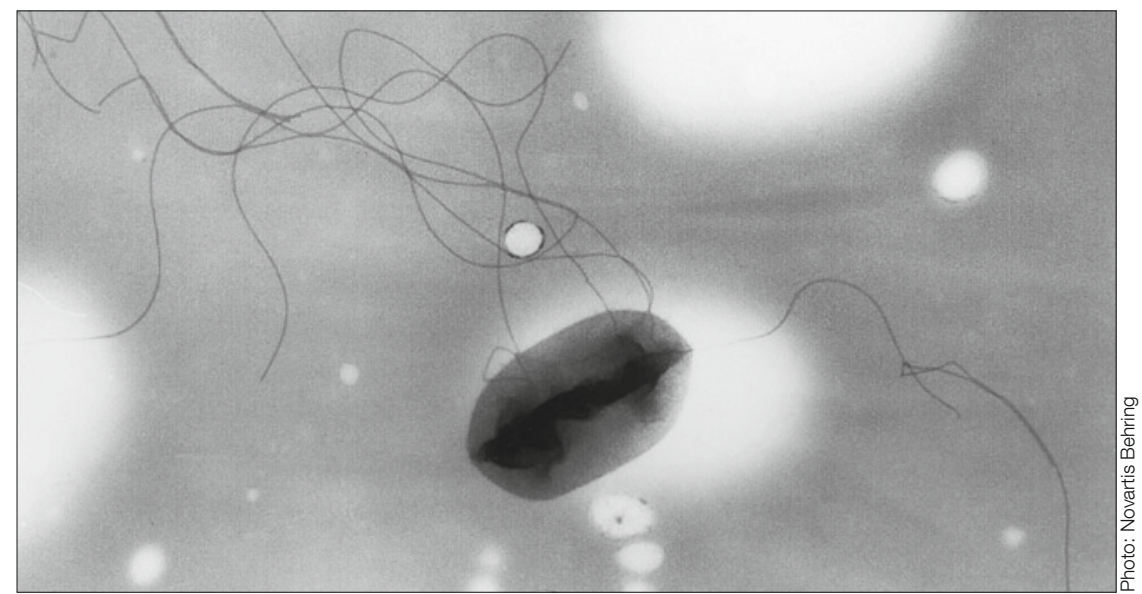

Auch E. Coli werden zunehmend resistent gegen die wichtigsten Antibiotika.

Die gestiegene Mobilität der Menschen bedeutet auch für multiresistente Bakterien eine erhöhte Mobilität. Das Auftreten einer Resistenz gegenüber mehreren Antibiotika in Ghana kann sich auch auf die Resistenzlage in Europa auswirken, stellte Prof. Jordi Vial, Mikrobiologe der Medizinischen Universität Barcelona und Programmdirektor des ECCMID fest. Dabei gehe es sowohl um Keime, die im Krankenhaus erworben werden, als auch um ambulant erworbene, und nicht ausschließlich um multiresistente Staphylococcus aureus (MRSA).

\section{„Wir brauchen neue Medikament!“}

Daten aus 900 europäischen Labors, die vom European Antimicrobial Resistance Surveillance System - EARSS gesammelt wurden, zeigten, dass Escherichia coli und Klebsiella pneumonia gegenüber den drei wichtigsten Antibiotika zur Behandlung invasiver Infektionen einschließlich Pneumonie und Septikämie zunehmend Resistenzen entwickeln. Eine kombinierte Resistenz gegen alle drei Medikamente ist ebenfalls im Steigen begriffen und könnte die größte Gefahr für die Spitals- ebenso wie für die ambulante Betreuung der Patienten in ganz Europa darstellen. Für gramnegative Keime seien derzeit wenig neue Medikamente in Aussicht, sagte Vial: „Wir brauchen neue Medikamente." Darüberhinaus stellte eine Studie aus den USA fest, dass der gefürchtete MRSA vermehrt auch außerhalb des Krankenhauses erworben wird. Innerhalb der zehnjährigen Studien- dauer zeigte sich eine Verdreifachung der ambulant erworbenen Infektionen und zwar in allen Altersgruppen, Patientensituationen und geographischen Regionen. Patienten mit ambulant erworbenen MRSA, die zur Behandlung ins Spital kommen, verursachen für die intramurale Resistenzlage ein zusätzliches und schwerwiegendes Problem.

Die modernen Therapien und das höhere Lebensalter in westlichen Gesellschaften führen zu einer wachsenden Zahl immungeschwächter Personen, die damit auch für Infektionen anfälliger sind. Das Noro-Virus beispielsweise, das für den $\mathrm{Pa}$ tienten ohne zugrundeliegender Erkrankung unangenehm, aber im allgemeinen nicht lebensbedrohlich ist, ist bei immungeschwächten Personen mit einem wesentlichen Mortalitätsrisiko verbunden. Krankenhäuser mit ihrer veränderten $\mathrm{Al}$ tersstruktur und alle Einrichtungen, in denen ein hoher Anteil alter und sehr alter Menschen zu finden seien, werden auch verstärkt mit diesem hochinfektiösen Virus konfrontiert sein, stellte Prof. Albert Osterhaus, Virologe vom Erasmus Medical Centre Rotterdam fest - vom Akutspital bis zum Kreuzfahrtschiff. Umso höheren Stellenwert gewinnt die Hygiene in diesen Einrichtungen, die zwar vor allem in Spitälern besser geworden ist, aber immer noch - vor allem bei den Medizinern - zu wünschen übrig lässt.

Quelle: ECCMID 2010, 10.-13. April 2010, Wien 